Cahiers $d u$ MONDE RUSSE

\section{Cahiers du monde russe}

Russie - Empire russe - Union soviétique et États indépendants

$55 / 3-4 \mid 2014$

Varia

\title{
Mark B. Smith, Property of Communists, The Urban Housing Program from Stalin to Khrushchev
}

\section{Hélène Richard}

\section{OpenEdition \\ Journals}

Édition électronique

URL : http://journals.openedition.org/monderusse/8097

DOI : 10.4000/monderusse.8097

ISSN : $1777-5388$

Éditeur

Éditions de l'EHESS

\section{Édition imprimée}

Date de publication : 1 juillet 2014

Pagination : 456-458

ISBN : 978-2-7132-2441-6

ISSN : $1252-6576$

\section{Référence électronique}

Hélène Richard, « Mark B. Smith, Property of Communists, The Urban Housing Program from Stalin to Khrushchev », Cahiers du monde russe [En ligne], 55/3-4 | 2014, mis en ligne le 14 avril 2015, Consulté le 24 septembre 2020. URL : http://journals.openedition.org/monderusse/8097 ; DOI : https://doi.org/ 10.4000/monderusse.8097

Ce document a été généré automatiquement le 24 septembre 2020.

(c) École des hautes études en sciences sociales 


\title{
Mark B. Smith, Property of Communists, The Urban Housing Program from Stalin to Khrushchev
}

\author{
Hélène Richard
}

\section{RÉFÉRENCE}

Mark B. SMITH, Property of Communists, The Urban Housing Program from Stalin to Khrushchev, Dekalb : Northern Illinois University Press, 2010, 252 p., 7 illus.

1 À partir d'une analyse de la genèse et du lancement du programme de construction de masse de logements urbains entre 1944 et 1964, Mark B. Smith s'interroge sur l'existence et la nature d'un État providence en Union soviétique. Si l'ouvrage répond globalement positivement à la question de l'existence, il s'attache surtout à en donner son trait distinctif et inattendu, à savoir des formes individuelles de propriété.

2 L'ouvrage est organisé autour d'une première partie chronologique (chapitres 1, 2, 3) plus descriptive et d'une seconde partie plus analytique (chapitres 4,5). Dans le chapitre 1 (1944-1950), l'auteur analyse l'impact destructif de la Seconde Guerre mondiale sur le stock de logements ainsi que les politiques de reconstruction en matière d'architecture et de rationalisation industrielle. Manquant de coordination, ces politiques ont un impact limité sur les conditions de logement de la population mais elles constituent le creuset du modèle qui prendra corps sous l'impulsion de Hruščev, notamment l'engagement en faveur de la construction standardisée d'appartements individuels destinés à une famille nucléaire. Le chapitre 2 (1951-1957) décrit le lancement du programme qui précède, en réalité, le célèbre décret de 1957 dans lequel le leader soviétique promettait un appartement séparé à tous les citoyens «dans un délai de dix à douze ans ». Le chapitre insiste sur le rôle personnel de Hruščev dans l'activation du modèle économique en germe, en raison de son expertise technique et de son implication étroite dans les discussions avec les architectes réticents à l'idée de 
préfabrication des matériaux. L'auteur souligne également cet aspect moins connu que fut l'importance de l'aide à la construction individuelle dans cette première étape du programme. L'explication par la volonté politique d'un homme nous semble cependant moins stimulante que les recompositions politiques et professionnelles, esquissées en début de chapitre, qui trouvent un point de fixation en la personne de Hruščev. La notion de rationalité sert de pivot à ce chapitre mais son statut varie : ce mot d'ordre que partage l'Union soviétique avec les démocraties occidentales à la même époque, l'auteur le reprend ensuite à son compte pour évaluer l'efficacité des mesures adoptées mais aussi la persistance d'«irrationalités ». Parmi elles, l'historien compte le rôle central des demandes individuelles de logement alors même que ces formes de communication entre le pouvoir et les citoyens semblent au centre de la rationalité - il faudrait plutôt parler de logique - du pouvoir soviétique, avant et après la guerre. Le chapitre 3 (1958-1964) traite de l'« idéologisation » du programme de construction de logement. Dans la perspective de l'avènement du communisme, la politique du logement s'accompagne d'un discours sur la réforme des hommes, volontarisme qui se fait au détriment de la qualité des logements et des infrastructures sociales. La seconde partie expose la thèse principale de l'ouvrage évoquée plus haut. Le court chapitre 4 propose un cours, ex cursus historique, conceptuel et comparatif, de la notion de propriété. Dans le chapitre 5 , l'auteur éclaire finement la manière dont l'après-guerre voit le lien des citoyens à leur logement renforcé, à la croisée de nouvelles conditions matérielles et de bases légales consolidées. Alors que le droit de propriété personnelle sur les maisons individuelles était une concession provisoire du régime aux nécessités de la reconstruction, le développement de l'habitat collectif consolide un mélange de propriété socialiste et de droits d'usage très étendus. Ce faisant, la rhétorique des droits est centrale dans les nombreux courriers de citoyens aux autorités, parfois au côté de références plus morales à la dette qu'aurait contractée la patrie à leurs égards pendant la guerre. L'auteur décrit précisément l'extension de ces droits d'occupation (formes spécifiques d'héritage, droit à l'échange, reflux des politiques de densification des appartements communautaires), leurs limites et surtout leur complexité. On pourra regretter que l'auteur ne montre pas l'originalité intrinsèque de cette construction juridique en parlant souvent de droits de propriété (property rights) ou de propriétaires de fait (de facto owners), là où il est question de droits d'usage très étendus et de liens subjectifs d'appropriation. Certains travaux en histoire du droit soviétique compléteront donc opportunément la compréhension des spécificités du cadre légal soviétique et l'intérêt d'en découvrir la logique interne plutôt que de la rabattre sur le vocabulaire de la propriété ${ }^{1}$. Il n'en reste pas moins qu'au-delà de ce choix de mot, l'auteur repère un phénomène intéressant, à savoir la conjonction d'une quasi-gratuité du logement et d'un fort attachement individuel aux choses immobilières, à la fois issu et garanti par un corpus juridique spécifique que les citoyens n'hésitent pas à mobiliser le cas échéant.

3 Finalement, cet ouvrage constitue un apport important pour la périodisation de l'histoire du logement en Union soviétique qui pourra servir utilement à des études plus spécifiques ou thématiques. L'auteur propose également de nombreuses données statistiques, présentées de manière critique qu'il cherche à contrôler par le croisement de sources ou la comparaison. La seconde partie constitue une proposition théorique stimulante qui vient compléter des travaux récents sur la réhabilitation de l'appropriation individuelle dans le creuset de l'après-guerre ${ }^{2}$. 


\section{NOTES}

1. Aurore chaigneau, Le droit de propriété en mutation : essai à la lumière du droit russe, P.: Dalloz, 2008.

2. Nathalie Moine, «Évaluer les pertes matérielles de la population pendant la Deuxième Guerre mondiale en URSS : vers la légitimation de la propriété privée? », Histoire \& mesure, XXVIII (1), 2013.

\section{AUTEURS}

\section{HÉLÈNE RICHARD}

UMR 5206 Triangle, Université de Lyon 